\title{
Rights of the People with Disabilities and Social Exclusion in Malaysia
}

\author{
M. Rezaul Islam
}

\begin{abstract}
This paper looks at the rights of the people with disabilities (PWDs) in the connection of social exclusion in Malaysia. The paper briefly reviews the current disability laws and national policies and find out the gaps and weaknesses of these documents. This paper shows how the rights of disabled people in Malaysia are associated with the process of social exclusion. By reviewing a number of studies, this paper offers a dimension of social exclusion, where the disabled people are depriving from their rights and excluding from the development arenas. The development practitioners, policy makers, and relevant governmental and non-governmental officials find some significant guidelines from this paper.
\end{abstract}

Index Terms-Disability, social exclusion, human rights, Malaysia.

\section{INTRODUCTION}

People with disabilities (PWDs) in Malaysia can be considered as one of the most vulnerable of the minority group in the Malaysian population [1]. WHO and World Bank (2011) estimated that there are $15 \%$ of the world population have some form of disabilities. According to the statistics from the Department of Social Welfare, the registered number of disabled people is 197,519 [2]. Total 359,203 disabled people were registered with the Department of Social Welfare in December 2012. Rashid mentioned that total number of disabled people in Malaysia is 305640 . Among them, 27,363 are visual, 39,303 hearing, 180 speech, 106,252 physical, 117,699 learning, 2,130 mental and 12,713 multiple disabled people [3]. However, these data are incomplete as registration of persons with disabilities in Malaysia is not compulsory, and is done only on a voluntary basis. In addition, the data are not up to date, as the names of those who have died are not deleted from the main record [4]. See and Hashim argue that the lack of a comprehensive database on the specific problems faced by people with disabilities in Malaysia poses a great challenge [5], [6]. The number of people with disabilities is expected to increase due to population ageing, rapid increase of chronic diseases and improvements in methodologies used to measure disability.

There are various forms of open discussion on the equal rights and the quality lifestyle of the people with disabilities in Malaysia. Their opinions are often excluded from the

Manuscript received September 27, 2013; revised December 25, 2013. This work was supported by the policy and social assessment for disenabled community in a multi-culture society - Malaysia. Sub-Program 2: Rights and Advocacy, No. of Project: RP003B-13HNE. Humanities \& Ethics (H\&E), Centre for Civilization \& Dialogue, University of Malaya.

M. R. Islam is with the Department of Social Administration \& justice, Universality of Malaya, 50603 Kuala Lumpur, Malaysia (e-mail: rezaul@um.edu.my). decisions that affect their welfare and livelihood. Most important thing is that a large numbers of disabled people are socially excluded in Malysia and they are now out of the main development stream [7]. There is no complete statistics on this number, but this process is very influential. Disablity in one hand and social exclusion in another, intesifies the lives of disabled people so challenging. Persons with disabilities are usually the nation's largest minority and they tend to be marginalized in all aspects of life. They usually experience substantially poorer quality of life and are more likely to be unemployed due to institutional discrimination [4]. Amar-Singh mentions a number of challenges of the disabled people, which include continued charity model with lack of respect, lack of uniform professional and quality services by the Health, Welfare \& Education Departments, growth of poorly trained professional manpower, lack of integration between various sectors, unhealthy rise in financially motivated services, and vulnerable segments of the population [8].

\section{Rights of DisABLED PeOPLE IN MALAysia: LEGISLATION AND POLICIES}

Historically, the concept 'disability' remained as one of the most neglected and forgotten development agenda by both the State and the non-state actors. They have always been considered as recipients of charity and welfare. By the late 90 's, almost all donors in the development field started changing their support from a service-delivery approach to a rights-based approach. From the 1970s onwards, academic discussions on disability and disabled people have moved away from a notion of impairment or 'handicap', and the concept of a social model of disability has been introduced. The social model arose as a reaction against the medical treatment of disability, which reduced disability to impairment so that disability was located within the body or mind of the individual, whilst the power to define, control and treat disabled people was located within the medical and paramedical professions. The introduction of the social model of disability was an attempt to readdress the power balance: disability was to be defined in the context of a disabling environment and disabled people were empowered as citizens with rights. At its inception, the social model was a political, rather than an academic approach, 'built on a basic rejection of the individual or medical approach, which puts the fate of disabled people solely in the hands of professional experts, particularly doctors, rehabilitation and social care staff' [9].

The Persons with disabilities (PWDs) are now entitled to exercise their civil, political, social, economic and cultural 
rights on an equal basis with others. At the global level, the latest achievement is the Convention on the Rights of Persons with Disabilities, the first legally binding disability-specific human rights convention; it is aimed at promoting, protecting and ensuring the full and equal enjoyment of all human rights and fundamental freedoms by PWDs [10]. The Convention, the Biwako Millennium Framework for Action and the Biwako Plus Five in 2008 provide an estimated 400 million persons with disabilities in the region with strong support which they can use to claim their rights and enjoy equal opportunities in terms of development and participation in society. Freedom of human rights has been stated in the Federal Constitution and the various acts in Malaysia. For example, Article 6 prohibits anyone to force others into slave labor. This means no one is allowed to force others to work for him. Every man is free to move and do anything legally. This means that even if a person with disabilities also is being given protection under the law in Malaysia. A right of PWDs in Malaysia has been recognized by introduction of Persons with Disabilities Act 2008. This Act came into force on July 7 , 2008. This law has given a new chapter for the people with disabilities when this act give a recognition the concept of "right-based" [11]. This act is a comprehensive document for the well fare and rights of the disabled people in Malaysia. The Part IV includes the promotion and development of the quality of life and wellbeing of disabled people. In this part, the chapter I mentions a number of accessibilities e.g. section 26- access to public facilities, amenities and services and buildings; section 27- access to public transport facilities; section-28- access to education; 29- access to employment; 30 - access to information, communication and technology; 31- access to cultural life; and 32- access to recreation, leisure and sport. The chapter 2 in Part IV includes habilitation and rehabilitation, chapter 3- health services, chapter 4- protection of persons with severe disabilities, and chapter 5- situations of risk and humanitarian emerge [12].

A number of national social welfare and social service policies secure the rights of the disabled people in Malaysia. The National Welfare Policy 1990 aims to create a stable and secure society, self-reliance, equalization of opportunities, fostering the spirit of mutual help, and support towards enhancing the caring culture. The National Social Policy 2003 emphasizes to enhance and ensure that persons with disabilities enjoy equal rights and full participation in the Malaysian society. The Policy focuses on 15 priority areas namely e.g. advocacy, health, rehabilitation, education, employment, personal safety and social protection, support services, social development, human resource, participation, research and development, housing, children and women disability, and accessibility. The objectives of the National Policy for Persons with Disabilities 2007 are to achieve social integrity and stability, national fortitude and well-being for a progressive and established Malaysian society. The National Plan of Action for Persons With Disabilities (2007-2012) has taken to enhance awareness and creating a positive attitude, a barrier-free environment, user-friendly transportation, access to information, health services, rehabilitation, education, employment and upgrading salary, protection from all forms of exploitation, capacity development and training, capability of NGOs, participation in planning and decision making processes. The Service Circular No 3 of 2008 has been initiated to implement of $1 \%$ Policy on Employment Opportunities for PWDs in the Public Sector.

If we review the provisions of the law and policies mentioned above, we may have a very positive impression that these are sufficient for the rights and welfare of the disabled people in Malaysia. But there are many gaps between these provisions. Mr. Maniam Sinnasamy, the Project Manager of the UNDP and Government of Malaysia Project stated that the needs of disabled persons in Malaysia are still seen largely as a welfare function of the state and non-government organizations. This 'welfare / charity' approach which is the basis of some of social policies such as the National Welfare Policy has come under severe criticisms from disabled people, because it views persons with disabilities as 'sick', 'not normal' or 'without abilities' and in need of charity and handouts. This approach tends to treat them as dependents, always in need of 'support' which society will give as and when it chooses [13]. We would argue that while this welfare/charity approach has contributed to some improvements in their well-being, this must now be replaced with the notion of equality and human rights in order to address the continuing violation of their fundamental rights. In addition, at the individual and community level, the absence of champions on disability rights issues and the lack of strong advocacy groups to influence decisions and policy makers remains a major challenge. While there is a need to promote awareness of the human rights of disabled persons, the inclusion of persons with disabilities in all stages of decision making is vital.

The Coalition of Malaysia NGOs in the UPR Process (COMANGO) stated that Malaysia signed the Convention on the Rights of Persons with Disabilities and there is adopted disability law, but it does not provide for rights of redress against those who discriminate against or fail to provide amenities for persons with disabilities [14]. Therefore, they continue to face real difficulties in accessing employment, education, housing, and public spaces and facilities. The majority of public transportation in the country is not disabled-friendly, and some are dangerous to be used. Despite the RM300 financial aid given by the Government to persons with disabilities who earn less than RM1,200 per month, it is still inadequate. Most persons with disabilities are unemployed and face rising medical costs. In the 2009 national budget, there was a provision of a monthly allowance of RM150 for those who are unable to work. This paltry sum allocated has been criticized as another example of policy making without consultation with people with disabilities. Khoo et al. argue that though the Malaysian Government has formulated and legalized various policies, legislations and initiatives, but these policies are not properly implemented [15]. For instance, policies like the General Order (PP 10/1988) that advocates and allots $1 \%$ of civil service positions to PWDs are merely policy statements without running its actual course. The lack of political will and commitment by the Malaysian Government to monitor and ensure proper implementation of existing PWD policies has negative ramifications for PWDs. Besides depriving PWDs employment opportunities that they rightfully deserve, 
the act of marginalizing and not integrating PWDs into the Malaysian workforce will in turn increase the dependency of PWDs on society (i.e. family, friends) and inevitably cause them to be trapped in the cycle of poverty indefinitely.

\section{SOCIAL EXCLUSION AND DISABILITY IN MALAYSIA}

Social exclusion is a "multidimensional phenomenon" having individual, social, economic, socio-economic, institutional and organizational, and political angles [16]. Islam \& Nath and Islam \& Sharmin stated that social exclusion“ is: (a) multidimensional, encompassing social, political, cultural and economic dimensions, and operating at different social levels; (b) dynamic, impacting in different ways to differing degrees at different social levels over time; and (c) relational, focuses on exclusion as the rupture of relationships between people and the society resulting in a lack of social participation, social protection, social integration and power [17], [18]. A relational perspective points to exclusion as the product of unequal social relationships characterized by differential power i.e. the product of the way societies are organized. DFID defined it as "a process by which certain groups are systematically disadvantaged because they are discriminated against on the basis of their ethnicity, race, religion, sexual orientation, caste, descent, gender, age, disability, HIV status, migrant status or where they live [19]. Discrimination occurs in public institutions, such as the legal system or education and health services, as well as social institutions like the household. Social exclusion is a process. It can involve the systematic denial of entitlements to resources and services, and the denial of the right to participate on equal terms in social relationships in economic, social, cultural or political arenas. Exclusionary processes can occur at various levels within and between households, villages, cities, states, and globally. This is an actor-oriented approach, which is useful because it points to who is doing what and in relationship with whom.

Now, it is the question whether disability is the product of social exclusion and how it is true in Malaysian context. There is lack of literature, which clearly argued that disability is the product of social exclusion. In the global context, there are a number of studies, which mentioned disability as a product of social exclusion. Nevertheless, most of the studies attempted to say that because of disability, the disabled people become excluded from the development arenas. As a result, they go faraway of their needs and rights. However, this an interesting academic debate around social exclusion and disability. Howard and O'grady et al. argue that of all the disadvantaged groups in society, the disabled are the most socially excluded... life opportunities remain severely restricted for many [20], [21]. The European Disability Forum (undated) stated that people with disabilities are undoubtedly among the most vulnerable at risk of social exclusion. The important factors that are contributing to social exclusion for people with disabilities are the lack or limited access to social environment and unemployment, the lack or limited access to goods and services, stigmatization of disabled people, the lack of adequate training, the lack of specialized services, the inadequacy of the education systems, the lack of economic policies to compensate for the extra cost of disability, the structure of the benefit system, and finally living in institutions. Jenkins \& Rigg and Burchardt have identified that the risk factors of disabled people who are older, have lower average household incomes, are more likely to be in the poorest fifth of the income distribution, are less likely to be in paid work, and have lower educational qualifications, on average [22], [23]. On the other hand, Duffy and Klasen mentioned that social exclusion is concerned with the 'inability to participate effectively in economic, social, and cultural life and, in some characteristics, alienation and distance from mainstream society [25]-[27]. Burchardt argues that from social model perspective disability' is seen as the social and economic disadvantage which results from society's failure to respond to the needs of people with impairments [23].

Room adds a new dimension to the discussion by couching the issue of social exclusion in a rights-based language when he talks about social exclusion as the 'denial or normalization of civil, political, and social rights of citizenship' [28]. Such a rights-based approach to the problem of social exclusion has much to recommend. It has great affinity with the capability approach developed by Amartya Sen, which calls for efforts to ensure that people have equal access to basic capabilities such as the ability to be healthy, well-fed, housed, integrated into the community, participate in community and public life, and enjoy social bases of self-respect [26], [27]. The term social exclusion would then be seen as the denial of the latter three important capabilities. First, it emphasizes that the inability to participate in, and be respected by, mainstream society is a violation of a basic right that should be open to all citizens (or residents). In contrast to poverty, which is often seen as a 'social' or 'welfare' issue, the rights-language considerably strengthens the case for society to ensure that it enables participation and integration of all its members [29]. As a result, there is less temptation to blame the excluded for their fate as is often the temptation in discussions about poverty and welfare. Instead, it highlights the role of political, economic and social arrangements in generating exclusion and the role of solidarity among members in overcoming it [30]. Second, it does not demand uniformity of outcomes, but instead calls for equal freedoms for all to enjoy all aspects of citizenship. Thus, it makes an important distinction between a choice of individuals to not participate in mainstream society, and their inability to do so. Conversely, social exclusion should not be fought by ensuring (or even demanding) participation, but by merely making it available to everyone. Third, it recognizes the diversity of people in their ability to make use of opportunities. For example, participation in mainstream society may be seriously constrained for people with physical and mental disabilities, as it could for people who are otherwise disadvantaged by birth or background. Thus, calling for equal capabilities (or the ability to exercise civil and social citizenship rights) may necessitate extra efforts by society to provide equal capabilities to such people. An equal starting point (or 'equal opportunities') may not be enough to ensure equal capabilities. Fourth, it focuses on ends and not on means. In this way, an important distinction can be drawn between a concern about income poverty and the concern about social 
exclusion.

The definition accepted by UNICEF in its 2006 report "Excluded \& Invisible" gives clearer picture how social exclusion exertions as a process of disability. It considers social exclusion as multi dimensional including deprivations of economic, social, gender, cultural and political rights making exclusion as a broader concept than material poverty. It considers Relativity (comparing circumstances of individuals and communities relative to others at a given place and time), Agency (act of an agent. Focus on the agency can help identify the cause of exclusion), and Dynamics (based on bleak future prospects and not on just current circumstances) as the three basic elements for exclusion. Disability fits into all the three elements of exclusion stated above.

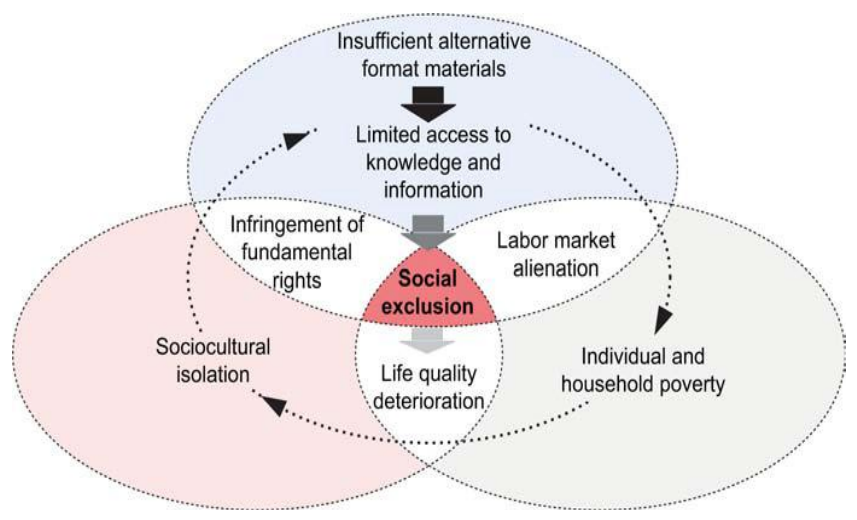

Fig. 1. Disability in social exclusion process, source: [31].

First, the access rights of persons with disabilities are considered to be composed of fundamental rights to education, labour and cultural activities (the right to use various modes of public transportation to ensure mobility, the right to use public facilities, the right to access information, etc.) with an aim to ensure equal opportunities and active participation in society. Without the rights of mobility, the right to use public facilities would mean very little. In addition, even if these two rights are both guaranteed, persons with disabilities would remain a socially marginalized group unless the right to access information centering on alternative format materials exists more than in name alone. Second, protecting the right to access alternative format materials will enhance the quality of living for persons with disabilities as well as social unity. By contrast, inadequate or insufficient alternative format materials and poor accessibility would serve to widen the information gap and lead to social exclusion. With the advent of the knowledge-based society and economy, the need to narrow the information gap among classes and between non-disabled and disabled persons, in particular, has emerged as a serious and urgent challenge. Inadequate and insufficient alternative format materials, which are a crucial part of the issue, can be regarded as the main culprits behind the social and cultural isolation of persons with disabilities as they limit access to knowledge and information and result in alienation within the labor market, individual and household poverty, and lowered overall quality of life as shown in Figure. Third, the development and provision of alternative format materials contributes decisively to eliminating the gap between disabled and non-disabled persons by improving information literacy among the disabled. Yoon \& Kim conducted a study concerning the information gap separating persons with disabilities over a four-year period reveal that persons with disabilities access, capability and use in terms of information is only 76 per cent of that of the total population, representing a gap of 24 per cent. However, based on previous evidences, we can conclude that disability is both process and product of social exclusion (See Fig. 1) [31].

Based on the theoretical and practical examples in global and Malaysian context discussed earlier, we have developed a dimension, which shows both sources and influential causal factors of social exclusion by which disabled people are socially excluded. We have identified three main levels such as family, community/social, and state levels as sources, where these exclusions occurred. The causal factors are interrelated with each other and it functions in different level with different meaning. We see that the social exclusion of disabled people first starts from their family, where they live with their parents, sisters/brothers, close relatives, and within family facilities and recreations. In Malaysian society, family is a very important social institution, where a child is born and brought up. It is seen that due to parents' poverty and unconsciousness, parents overprotect their disabled children. They think them burdens. Due to their lack capacity, they also ignored by their normal sisters and brothers. As a result, the disabled children get lower facilities including all basic needs than normal children. They also deprive from their relatives due to their fear, ignorance and devaluation. However, at family level a disabled child start with low care including physical, mental and emotional development and they are being developed with inadequate family environment. This process isolates disabled children at the family level.

At the community and social level, both the sources and causal factors of such exclusion expand a lot. Here, the exclusion is happened within the relationships and activities with the neighbours, friends, and social networks and within their community level movement \& transport, and sports \& recreation. In Malaysian society, disability is still considered as a sin of God, Social prejudices, social ignorance, social stigma, segregation, devaluation, lack of capacity, lack of social acceptance, religion and cultural barriers, etc. are very influential factors. The Fig. 2 shows that in most of the sources, the disabled people are affected by these causal factors. As a result, the disabled people feel them shame, fear, and lack of dignity. The whole process does isolate them from the community/society. At community level, there are not sufficient facilities such as unfriendly road and transport, unfriendly human environment, lack of there necessary equipments e.g. wheelchair, the disabled people could not participate in many social functions such as social networks, sports and recreation. Poverty and lack of capacity are more influential factors at this level, which isolate them from all community and social activities.

At the state level, the main sources of social exclusion are happened in public facilities, education, health services, employment, ICT, and legal facilities. For example, due to the lack of individual capacity, social ignorance, unfriendly environment, inaccessible communication and transport, the 
disabled people cannot avail many public facilities. Poverty, lack of government supports, lack of institutions and teachers, and high cost of private facilities, disabled people are deprived from education. On the other hand, lack of education and skills, lack of proper quota, lack of government care, devaluation, and social ignorance, they are not getting employment facilities from the state. The ICT (information, communication, and technology) is not placed in the country according to the needs and demands of the disabled people. They are not getting proper legal facilities from the state. In this stage, we argue that all of the mentioned causal factors are interacting at a cyclic order, where one cause is producing same cause at different level. For example, due to the lack of opportunities from the family, they stay with low quality and because of low quality, they do not get proper access in the community which helps to keep them again lower quality, and because of lower quality, they are not capable to receive public facilities such as health, employment, recreation, etc. At this stage, as we mentioned earlier, the state considers the rights of the disabled people from the 'welfare/charity' approach. We can compare this with the medical or need based approach. The state provides supports to the disabled people according to their needs or services. Due to this practice, the rights of the disabled people are not improving at all though the state formulated disabled law and a number of welfare policies for them. However, this proposed dimension (See Fig. 2.) is related with the social model as well as the right based approach. Many of the factors and sources are also related with the comments made by Sen and Room [25]-[27]. This is a comprehensive dimension, which include all of the sources and causal factors of disability and show how the disabled people are excluded from their needs and rights. Here, the argument is that the rights of the disability are not related with the incapability of the disabled people, as they are the product of the society or state. However, this dimension emphasizes that the disabled people are not accountable or responsible to secure their own rights and needs by themselves rather it is the responsibility of the society or state.



Source: Author

Fig. 2. Sources and factors of social exclusion and connection of the violation of disability rights. 


\section{CONCLUSION}

To consider the overall discussion above, we can say that there are disability act, social exclusion act, and welfare policies for fulfilling the needs and rights of the disabled people in Malaysia. But we have seen through reviewing a number of literatures that the disabled people in Malaysia are excluded from the main stream development and their socio-economical conditions are poor. The important thing is the question of their rights according to the disability law, social exclusion law, national policies, and international conventions which are ratified by the Malaysian Government. Another question is inclusive development. In both cases, disability issue has come in the front of national development. To consider a number theoretical and practical approaches, this paper offers a dimension of social exclusion which is more comprehensive, complete and effective to see the disability issue as a process of social exclusion. This dimension gives more details with sources and interacting causal factors where disabled people are continuously excluded from the development stream, and their rights are violating and it becomes a big national concern. The policy makers, development practitioners, and GO-NGO workers may get some significant aspects from this dimension. This dimension provides the causal factors and sources of the social exclusion and show how the disabled people are within this process. This paper concludes the statement by Laurin-Bowie [32]. He said that to understand why people with disabilities continue to be among the most disadvantaged people in the world we must consider how people with disabilities are perceived by policy makers and how development policy addresses disability. If real progress is to be made in achieving better lives for people with disabilities both the perception of people with disabilities and policy objectives must change.

\section{ACKNOWLEDGMENT}

M. R. Islam thanks to the University of Malaya to provide the research funding for this study.

\section{REFERENCES}

[1] K. Kamaruddin, "Adult learning for people with disabilities in Malaysia: Provisions and services," The Journal of Human Resource and Adult Learning, vol. 3, no. 2, pp. 5-64, 2007.

[2] Department of Social Welfare, Rehabilitation Centre for the Orthopedically Handicapped Centre, Legal and Advocacy Division, Kuala Lumpur, Malaysia, 2006.

[3] M. Z. Rashid, "Empowering persons with dsiabilities in Malaysia," 10th BJM of teh East Asia Pacific Regional Council of Cheshire Home, pp. 8-11, October, 2010.

[4] T. L. Ta, L. L. Wah, and K. S. Leng, "Employment of people with disabilities in the Northern States of Peninsular Malaysia: Employers' perspective," Disability, CBR and Inclusive Development, vol. 22, no. 1, pp. 79-94, 2011.

[5] C. M. See. (2011). Employment of people of the disabilities in Malaysia:Drivers and inhibitors. [Online]. Available: http://www.file://C:/Users/user/Desktop/Disability/See\%20(2011).ht $\mathrm{m}$

[6] N. M. Hasim, "Persons with Disabilities Act 2008: Promotion of social inclusion for PWDs in Malaysia," presented at the Perspective of Inclusive Development: Embracing Diversity and Creating Disability Communities, 28-29 July, Kuching, Sarwak, Malaysia, 2010.

[7] M. Care. (2013). People with special needs. [Online]. Availabale: http://www.malaysiancare.org.my/index.cfm?menuid $=12$

[8] H. S. S. Amar Singh. (2010). Whither (Wither?) services for children with disability in Malaysia. [Online]. Available:
http://agapesibu.org/wp-content/uploads/2012/07/Whither-Services-fo r-Children-with-Disability-in-Malaysia.pdf

[9] C. Barnes, "Disability and employment," Personnel Review, vol. 21, no. 6, pp. 55-73, 1992.

[10] United Nations. (2008). Convention on the Rights of Persons with Disabilities. [Online]. Available: http://www.un.org/disabilities/convention/conventionfull.shtml

[11] H. J. B Jaafar, H. A. Wahab, and H. Omar, "Right of the disabled persons under Persons with Disabilities Act 2008: A case study in the state of Perlis," Business and Information, pp. 407-417, July 7-9, 2013

[12] Persons with Disability Act 2008, Persons with Disability Act 2008, Malaysia: Government of Malaysia, 2009.

[13] DNIS. (2013). The needs of disabled persons in Malaysia are still seen largely as a welfare function. [Online]. Available: http://www.dnis.org/print_interview.php?interview_id=150

[14] COMANGO (Coalition of Malaysia NGOs in the UPR Process), Universal periodic review on Malaysia, presented at the $4^{\text {th }}$ session of UPR, Kuala Lumpur, Malaysia, February 2009.

[15] S. L. Khoo, T. L. Ta, and L. W. Lee, "The Role of the state towards employability of Malaysian PWDs - Myth or reality?" World Academy of Science, Engineering and Technology, vol. 66, pp. 1102-1107, 2012.

[16] E. A. Maldonado, N. A. Pogrebnyakov, and A. F. van Gorp, "ICT policies as a means to inhibit social exclusion: the South African case," in Social Inclusion: Societal and Organizational Implications for Information Systems, E. Trauth. Eds, Springer, New York, NY, 2006, pp. 137-50.

[17] M. R. Islam and B. Nath, "Socially excluded people in Bangladesh: Causes and processes," American Journal of Social Issues and Humanities, vol. 2, no. 5, pp. 355-367, 2012.

[18] M. R. Islam and K. Sharmin. "Social exclusion in non-government organizations' (NGOs') activities in Bangladesh," Sociology Mind, vol. $1 \& 2$, pp. 36-44, 2011.

[19] DFID. (2005). Reducing poverty by tackling social exclusion: A DFID Policy Paper. [Online]. Available: http://www.gsdrc.org/go/display\&type=Document\&id=1568

[20] M. Howard. "Social exclusion zone," The Guardian, July 28, 1999.

[21] A. O'grady, P. Pleasence, N. J. Balmer, A. Buck, and H. Genn, "Disability, social exclusion and the consequential experience of justifiable problems," Disability and Society, vol. 19, no. 3, pp. 259-272, 2004.

[22] S. Jenkins and J. Rigg, "Disability and disadvantage: selection, onset and duration effects," Institute for Social and Economic Research working paper no. 2003-18, Colchester: University of Essex, 2003.

[23] T. Burchardt, Being and Becoming: Social Exclusion and the Onset of Disability, London: London School of Economics, 2003.

[24] K. Duffy, Social Exclusion and Human Dignity in Europe, Council of Europe, 1995 ,

[25] S. Kalsen. (1998). Social exclusion and children in OECD countries: Some conceptual issues. [Online]. Available: http://www.oecd.org/edu/school/1856923.pdf

[26] A. Sen, "Justice: Means versus freedoms," Philosophy and Public Affairs, vol. 19, no. 2, pp. 11-119, 1990.

[27] A. Sen, Inequality Reexamined, Cambridge: Harvard University Press, 1992

[28] G. Room, Beyond the Threshold. The Measurement and Analysis of Social Exclusion, Bristol: Polity Press, 1995.

[29] A. Walker, "Poverty in the UK, in Britain Divided: The Growth of Social Exclusion in the 1980s and 1990s," A. Walker, and C. Walker, Eds. London: Child Poverty Action Group, 1997.

[30] H. Y. Yoon and S. Y. Kim, "Development strategy of the alternative format materials for disabled people in Korea," Aslib Proceedings: New Information Perspectives, vol. 63, no. 4, pp. 380-398, 2010

[31] C. L. Bowie, "Poverty," Disability and Social Exclusion: New Strategies for Achieving Inclusive Development, USA: Cornell University, 2005.

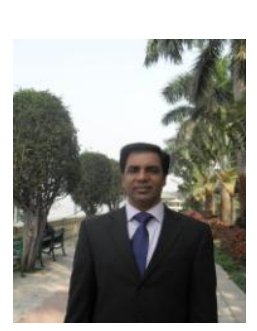

M. R. Islam was born at Kushtia in Bangladesh on 21 September 1969. He has earned his BSS Honours in 1990 and Masters in 1991in Social Welfare from the University of Dhaka, Bangladesh and MSW in 2005 and $\mathrm{PhD}$ in 2009 from the University of Nottingham, England. His major fields of interest include social research methodology, poverty and human rights, child welfare, social policy, and social development.

He has taken a number of national and international assignments including teaching in abroad and research works with many international organizations i.e. World Bank, UNDP, UNICEF, UNESCO, 
ILO, DFID, European Union, Concern Worldwide, Concern Universal, Asian Development Bank, etc. He is now professor at the Institute of Social Welfare and Research, University of Dhaka, Bangladesh (from December 2012). At present he is a visiting senior lecturer at the Department of Social Administration \& Justice, University of Malaya, Malaysia (from December 2012). He has written a number of books published from reputed publishers i.e. Women Perception on Violence and Discrimination in Bangladesh (Germany, Lambert Publishing, 2011), Situation of Domestic Child Workers in Dhaka City (Dhaka, Bangladesh, Shishi Adhikar Forum, 2010), and
Substance Misusing Children: Parents' Role in Helping Them (Germany, Lambert Publishing, 2010). His previous and present research interest include poverty and human rights, child welfare, and social development.

Dr. Islam is a gust editor of the Malaysian Journal of Social Administration in the forthcoming special issue which covers child maltreatment. He worked as a member of editorial board of many international journals and he reviews many ISI ranking journals' papers regularly. 